Groot, K. de, Maurits, E.E.M., Francke, A.L. Attractiveness of working in home care: an online focus group study among nurses. Health and Social Care in the Community: 2018, 26(1) e94-7 e101

\begin{tabular}{|l|l|}
\hline $\begin{array}{l}\text { Postprint } \\
\text { Version }\end{array}$ & 1.0 \\
\hline $\begin{array}{l}\text { Journal website } \\
\text { Pubmed link }\end{array}$ & $\frac{\text { http://onlinelibrary.wiley.com/doi/10.1111/hsc.12481/abstract;jsessionid=54CC94 }}{\text { hC19A17731D27202F87423ECB0.f03t01 }}$ \\
\hline $\begin{array}{l}\text { DOIww.ncbi.nlm.nih.gov/pubmed/28730631 } \\
\text { This is a NIVEL certified Post Print, more info at } \text { http://www.nivel.eu }\end{array}$ \\
\hline
\end{tabular}

\title{
Attractiveness of working in home care: An online focus group study among nurses
}

\author{
KIM DE GROOT, MSC (RESEARCHER, RN) ${ }^{1,2}$, ERICA E.M. MAURITS, MSC \\ (RESEARCHER) ${ }^{1}$, ANNEKE L. FRANCKE, PHD (PROFESSOR, NURSING CARE PROGRAMME \\ COORDINATOR $)^{1,3}$ \\ 1. Netherlands Institute for Health Services Research (NIVEL), Utrecht, the Netherlands \\ 2. Thebe Wijkverpleging [Home care organisation], Tilburg, the Netherlands \\ E-mail address: k.degroot@nivel.nl \\ 3. Amsterdam Public Health Research Institute, VU University Medical Centre, Amsterdam, \\ The Netherlands
}

\begin{abstract}
Many Western countries are experiencing a substantial shortage of home-care nurses due to the increasing numbers of care-dependent people living at home. In-depth knowledge is needed about what home-care nurses find attractive about their work in order to make recommendations for the recruitment and retention of home-care nursing staff. The aims of this explorative, qualitative study were to gain in-depth knowledge about which aspects home-care nurses find attractive about their work and to explore whether these aspects vary for homecare nurses with different levels of education. Discussions were conducted with six online focus groups in 2016 with a total of 38 Dutch home-care nurses. The transcripts were analysed using the principles of thematic analysis. The findings showed that home-care nurses find it attractive that they are a "linchpin", in the sense of being the leading professional and with the patient as the centre of care. Home-care nurses also find having autonomy attractive: autonomy over decision making about care, freedom in work scheduling and working in a self-directed team. Variety in patient situations and activities also makes their work attractive. Home-care nurses with a bachelor's degree did not differ much in what they found attractive aspects from those with an associate degree (a nursing qualification after completing senior secondary vocational education). It is concluded that autonomy, variety and being a "linchpin" are the attractive aspects of working in home care. To help recruit and retain home-care nursing staff, these attractive aspects should be emphasised in nursing education and practice, in recruitment programmes and in publicity material.
\end{abstract}


Groot, K. de, Maurits, E.E.M., Francke, A.L. Attractiveness of working in home care: an online focus group study among nurses. Health and Social Care in the Community: 2018, 26(1) e101

\section{What is known about this topic}

- Many Western European countries are finding it a challenge to ensure a sufficiently large workforce in home care.

- Autonomy is the aspect most frequently mentioned in the research literature on the attractiveness of working in home care.

- In-depth knowledge about what makes working in home care attractive is lacking.

\section{What this paper adds}

- Being a "linchpin", autonomy and variety in patient situations and nursing activities are attractive aspects of working in home care.

- Attractive aspects are largely identical for home-care nurses with a bachelor's degree and those with an associate degree.

- Attractive aspects should be emphasised in publicity materials and by managers, lecturers, recruiters and policy makers.

\section{INTRODUCTION}

Western populations are aging rapidly, a development that is accompanied by an increasing prevalence of chronic diseases (European Commission 2013; United Nations 2013). Most chronically ill and elderly people prefer to receive care at home (Genet et al., 2011). In addition, European countries' governments generally promote home care rather than institutional care, which is leading to a growing demand for home care (Genet, Boerma, Kroneman, Hutchinson, \& Saltman, 2012).

While the demand for home care is increasing, many Western European countries are experiencing a substantial shortage of home-care nurses (EUROFOUND 2013, Genet etal., 2012). Home-care nurses deliver nursing care to patients at home. Nursing care ranges from personal care in daily activities to technical nursing care, preventive care and psychosocial care, for short or long periods. For a sufficiently large workforce, it is important to recruit new home-care nurses and to prevent current staff from leaving the home-care sector. Healthcare professionals, managers, lecturers, recruiters and policy makers therefore need to have information on the specific attractive aspects of working in home care.

However, little research has been done on the aspects that attract nurses to working in home care. Autonomy is the aspect most frequently mentioned in the scarce research literature on the attractiveness of working in home care (Anthony \& Milone-Nuzzo 2005, Ellenbecker, 2004; Ellenbecker, Boylan, \& Samia, 2006, Maurits, De Veer, Van der Hoek \& Francke, 2015; Tummers, Groeneveld, \& Lankhaar, 2013). Autonomy can be defined as "independence and freedom of initiative in a job" (Ellenbecker, 2004), and can be divided into: (i) autonomy over patient care, which refers to individual authority and freedom to make decisions concerning the content of patient care; (ii) work autonomy, which includes freedom and discretion in work scheduling and work methods; and (iii) organisational autonomy, which includes decision making about the practice setting and contextual matters (Weston, 2008). Two surveys and a literature review from the US showed that autonomy is the most frequently reported positive aspect of working as a homecare nurse (Anthony \& Milone-Nuzzo 2005, Ellenbecker 2004; Ellenbecker et al., 2006). Two Dutch surveys also revealed autonomy to be an attractive aspect (Maurits 
Groot, K. de, Maurits, E.E.M., Francke, A.L. Attractiveness of working in home care: an online focus group study among nurses. Health and Social Care in the Community: 2018, 26(1) e94-7 e101

et al. 2015, Tummers et al. 2013), and showed that it is related to the intention to remain working in the healthcare sector.

With regard specifically to organisational autonomy, the rise of self-directed teams in Western countries is an interesting trend (Gray, Sarnak, \& Burgers, 2015; Maurits, De Veer, Groenewegen, \& Francke, 2017; Tjepkema 2003). A "self-directed team" can be described as a team of home-care nurses that organises nursing care independently, in an optimum way for their patients and without directions from a manager. Self-directed teams differ from traditional teams in which managers have more influence on the nursing care and practice setting (Gray et al. 2015, Tjepkema 2003). Furthermore, working in these self-directed teams is associated with enhanced autonomy over patient care (Maurits et al. 2017).

Previous research also points to some other aspects that attract nurses to work in home care, such as good employment conditions, use of their skills and abilities, having sufficient time to provide high quality nursing care, supportive supervisors and flexibility (Amstrong-Stassen \& Cameron 2005; Anthony \& Milone-Nuzzo 2005, Tourangeau, Patterson, Saari, Thomson, \& Cranley, 2015). However, previous studies on the attractive aspects of working in home care were mainly quantitative in nature, and in-depth knowledge of what attracts home-care nurses is lacking, for instance with regard to the kind of autonomy that home-care nurses find attractive. This knowledge is needed in order to be able to give recommendations for recruiting and retaining home-care nursing staff.

Therefore, the qualitative study described in this paper aims to provide in-depth knowledge on the attractive aspects of working in home care. The study was performed in the Netherlands, a country with an urgent need for more home-care nurses. In the Netherlands, nurses either have an associate degree (a nursing qualification after completing senior secondary vocational education) or a bachelor's degree (from a university of applied sciences). We were interested to see whether there are differences between home-care nurses depending on their level of education in what they find attractive about working in home care. This is relevant since homecare nurses with a bachelor's degree are assigned a central position in the community in governmental and professional policy documents in the Netherlands (De Bont, Van Haaren, Rosendal \& Wigboldus, 2012; Ministry of Health, Welfare and Sports 2015), while this is less so for their colleagues with an associate degree. In particular, home-care nurses with a bachelor's degree, but not those with an associate degree, have the legal authority to perform a formal care needs assessment to decide what type of care and how much home care has to be delivered to a patient. The aspects that home-care nurses find attractive in their work might therefore also depend on their level of education.

This led to the following aims of this study:

- To gain in-depth knowledge about which aspects home-care nurses find attractive about their work.

- To explore whether these aspects vary for home-care nurses with different levels of education. 
Groot, K. de, Maurits, E.E.M., Francke, A.L. Attractiveness of working in home care: an online focus group study among nurses. Health and Social Care in the Community: 2018, 26(1) e101

\section{METHODS}

\subsection{Design}

An explorative, qualitative design was used with online focus groups (OFGs). OFGs were chosen rather than traditional face-to-face focus groups, because OFGs give the participants the ability to participate at a time most convenient to them. Additionally, OFGs enable participants to be recruited from a broad geographical area, because they can participate from home (Reid \& Reid 2005, Tates et al. 2009, Zwaanswijk \& Van Dulmen 2014).

\subsection{Participants and recruitment}

Participants were eligible for inclusion if they met the following criteria:

1) Being a registered nurse with a bachelor's degree or an associate degree in nursing,

2) Currently providing home care, and

3) Having access to and being able to use a device with an Internet connection.

Participants were recruited through convenience sampling, by using professional associations' social media, the network of an alumni association and the professional network of the principal researcher (K.G.), as well as through 'snowball sampling'. Additionally, home-care nurses of a pre-existent Dutch research panel of nursing staff (see https://www.nivel.nl/en/panel-nurses-carers-vv) were asked whether they were prepared to participate in this specific study. This recruitment resulted in an initial sample of 85 home care nurses who stated that they were potentially interested in participating. These 85 nurses received information about the study and an informed consent form by e-mail. In total, 38 nurses (44.7\%) signed and returned the informed consent form.

\subsection{Data collection}

The participants were divided into two homogeneous OFGs of home-care nurses with a bachelor's degree, two homogeneous OFGs of home-care nurses with an associate degree and two heterogeneous OFGs of nurses with both types of degree. We chose to have some heterogeneous OFGs since we expected that these would provide participants with an opportunity to discuss with nurses with a different level of education whether they differed in what they found attractive in their work. On the other hand we expected that the homogenous OFGs would provide opportunities for nurses with the same level of education to supplement one other regarding aspects which they found attractive.

Previous research showed that two OFGs with about eight participants were sufficient to gain worthwhile insights about aspects of working in home care (De Putter, Francke, De Veer \& Rademakers, 2014). Therefore, it was expected that six focus groups, each with six to eight participants, would be more than enough to reach data saturation, the point where new data collection does not provide any new insights relevant to the research questions (Guest, Bunce, \& Johnson, 2006). Discussions with the six OFGs were organised between February and May 2016, using a closed web-based discussion site developed by NIVEL - the Netherlands Institute for Health Services Research (Tates et al. 2009). Participants received an email with the starting date of the OFG discussion, the website link and their 
Groot, K. de, Maurits, E.E.M., Francke, A.L. Attractiveness of working in home care: an online focus group study among nurses. Health and Social Care in the Community: 2018, 26(1) e94-7 e101

individual login names and passwords. The OFG discussions were conducted in an asynchronous form, meaning in this case that participants could log in, read each other's anonymous comments and give their written online responses at any time within a set period of two weeks. Each of the six OFG discussions started with the open question "What do you find attractive about your work as a home-care nurse?". Thereafter the research team asked more specific questions, steered by the answers to the first question and based on the interview guide shown in Table 1.

\section{[ TABLE 1]}

Questions from the interview guide were placed on the discussion board every two days, except in the weekend. The research team acted as moderators by regularly checking the comments and posting new questions. The research team consisted of three members: the principal researcher, a nursing scientist who also works on a part-time base as a home-care nurse (K.G.), a researcher on the working conditions of nursing staff (E.M.), and a nursing professor and research coordinator (A.F.).

\subsection{Data analysis}

The OFG transcripts were analysed following the steps of thematic analysis: becoming familiar with the data, generating initial codes, searching for themes, reviewing themes, defining and naming themes and producing a report (Braun \& Clarke 2006). Thematic analysis was used because this is a flexible and systematic method for identifying themes within qualitative data (Braun \& Clarke 2006, 2014). The transcripts of all six OFG discussions were analysed by the principal researcher (K.G.), while the first four OFG discussions were also independently analysed by one of the other two researchers (A.F. or E.M.). The initial codes derived from the independent analyses were discussed until consensus was reached. After searching for and reviewing themes, a thematic 'mind map' was drawn. This map was discussed with the research team until consensus was reached about the defining of themes. This resulted in Figure 1 and the themes discussed in the Results section.

\subsection{Ethical considerations}

The study was conducted in compliance with the principles of the Dutch Personal Data Protection Act (see http://www.privacy.nl/uploads/guide_for_controller_ministry_justice.pdf). The anonymity of the participants was strictly safeguarded throughout the entire study. Further ethical approval of this study was not required under the applicable national Dutch legislation since all participants were competent individuals, they were not subjected to procedures and they were not required to follow rules of behaviour (for the Dutch legislation, see: http://www.ccmo.nl/en/).

\section{FINDINGS}

The background characteristics of the 38 participants of the OFG discussions are shown in Table 2.

\section{[TABLE 2]}

The three main themes and the related subthemes in Figure 1 will be discussed in the next sections. 
Groot, K. de, Maurits, E.E.M., Francke, A.L. Attractiveness of working in home care: an online focus group study among nurses. Health and Social Care in the Community: 2018, 26(1) e94-7 e101

\section{[FIGURE 1]}

\subsection{Linchpin}

Home-care nurses considered themselves as a "linchpin" in the community in the sense that they had a central position in the community, communicating and collaborating with general practitioners, other professionals (e.g. from welfare and municipal organisations) and family caregivers. From this position they saw the patient as the centre of care and themselves as the leading professional in the care for their patients as well as within the community. Participants considered themselves as 'leading' since they formed the link between the patient and other professionals (e.g. general practitioners, nursing assistants and home helps) and were responsible for the coordination of care and for the wellbeing of their patients and family caregivers. Their role as linchpin was also attractive for them since it let them make a positive difference to the situation of their patients.

"I like to be the one who makes the connections around the patient, the one who assesses the care needs and the one who takes actions to connect the patient to professionals and to family caregivers. If this eventually leads to a good collaboration, it can give me a lot of satisfaction." (OFG 3, homogeneous OFG, bachelor's degree)

Their perception of the patient as the centre of care and their role as linchpin also meant that participants took the needs of patients and their relatives as the starting point of care rather than the rules of their organisation. This was why patients appreciated them.

"I see that the patient (almost) always looks forward to our visits. They like us because the things that nurses do complement the things a patient cannot get done independently. The care is a (small) part of his/her life." (OFG 2, heterogeneous OFG)

Home-care nurses in all the OFGs - the homogeneous as well as the heterogeneous OFGs - emphasised that the "linchpin role" (irrespective of whether or not they used this specific term) was attractive for them. However, some specific subroles were associated with the educational level. Home-care nurses with a bachelor's degree referred to their role coaching team members as an attractive aspect, but this was not mentioned by their colleagues with an associate degree.

\subsection{Autonomy}

In all OFGs, home-care nurses mentioned autonomy as an attractive aspect of their work. First of all, autonomy was about the autonomy over patient care. Participants said that they had a relatively autonomous role in decision making about the care needed. At the same time, participants in all OFGs said that shared decision making with the patient and the family caregivers was 'a must'. In addition, decision making was also related to the "linchpin role" and as such influenced by consultations with colleagues and other relevant professionals, such as general practitioners. "What I really like is that I can consult a lot with colleagues and other disciplines, but when decisions have to be made I have an important role too." (OFG 1, homogenous OFG, bachelor's degree)

With regard to autonomy over patient care, home-care nurses with a bachelor's degree mentioned their authority to perform formal care needs assessments; the home care nurses with an associate degree do not have this authority, but they did recognise this as an aspect for their colleagues with a bachelor's degree. 
Groot, K. de, Maurits, E.E.M., Francke, A.L. Attractiveness of working in home care: an online focus group study among nurses. Health and Social Care in the Community: 2018, 26(1) e94-7 e101

Secondly, home-care nurses with a bachelor's degree and those with an associate degree mentioned that work autonomy was attractive. For example, they stated that being able to schedule their activities and set priorities was important for them. Their relative independence in scheduling most of their activities made their work challenging in the positive sense of the word.

"Independent scheduling of your own tasks and setting priorities is a nice part of our work. It means that you constantly have to check your own schedule and have to make compromises on a regular basis. That means that you never know beforehand how your day is going to be." (OFG 2, heterogeneous OFG)

Thirdly, aspects of organisational autonomy were mentioned, particularly in relation to working in self-directed teams. Several home-care nurses with either a bachelor's degree or an associate degree who worked in self-directed teams called their team their "own business" or their "own shop". They found that working in a self-directed team made it possible to be responsible for their own work together with their team members and not to be dependent on a manager. This independence made their work more attractive, and some said that they never wanted to return to a traditional, nonself-directed team.

"I have worked in a self-directed team since 2013 and it has opened up a whole new world for me. I was used to managers who did not reply to questions or only did so after a long time. I often felt I was not being taken seriously. Now, in this selfdirected team, I help to come up with solutions and feel responsible for everything we encounter in our work, together with my colleagues." (OFG 2, heterogeneous OFG)

Home-care nurses found that self-direction resulted in more equality and involvement among the team members. They said that self-direction allowed them to make use of each other's qualities, to develop these qualities and to 'flourish'. "Everyone is important in a self-directed team. Nobody can be missed, which makes everyone so valuable with their own individual qualities and experiences." (OFG 4, heterogeneous OFG)

However, a few participants made remarks about the necessary preconditions for a self-directed team: it was important to have the trust of the authorities higher up in the organisation and the right facilities, and if these preconditions were not satisfied, this reduced the attractiveness of self-direction. Additionally, not all participants liked the idea of working in a self-directed team. For instance, one nurse working in a traditional, non-self-directed team mentioned that she liked the possibility of falling back on someone else and the safety of support from the authorities.

\subsection{Variety}

Participants of both educational levels said that every working day was unique because of the variety in their work. First, there was variety in the patient situations. In all OFGs - the heterogeneous as well as the homogenous OFGs - the variety in patient situations was mentioned as an attractive aspect of working in home care. The participants stated that each situation was unique and required different solutions or actions. Several participants mentioned that the varied patient situations required constant alertness during nursing care and stopped their work from becoming a boring routine. In addition, given that home care is delivered in the patients' home, they also found having to take account of the rituals and wishes of each individual patient an attractive aspect. 
Groot, K. de, Maurits, E.E.M., Francke, A.L. Attractiveness of working in home care: an online focus group study among nurses. Health and Social Care in the Community: 2018, 26(1) e94-7 e101

"I like the fact that each patient situation is different. I have to deal with people of different ages. They might be wealthy or they might be just getting by. They might be intelligent or illiterate. They might be mature and help come up with ideas or they might leave the initiative to others. You have to deal with the family around a patient, but also with patients with almost no family. Seriously ill, terminally ill, but fortunately sometimes you also get to end the care because the patient is cured." (OFG 2, heterogeneous OFG)

Second, the variety in activities was considered an attractive aspect. This aspect was mentioned in all OFGs. In particular, the combination of nursing care for their patients and the more organisational activities was frequently mentioned as an attractive aspect.

"Caring for the patients, directing the nursing care by taking a helicopter view, coaching and managing the team and contributing to improvements in the quality of care within the team and the organisation. It is incredibly diverse. Every day I switch continuously between these different roles, it's wonderful!" (OFG 1, homogenous OFG, bachelor's degree)

Home-care nurses saw these varied activities as inherent to their role as a "linchpin". Home-care nurses found that the variety in patient situations and nursing activities led to a certain alertness, improvisation, flexibility and creativity in their work. Home-care nurses said that standard solutions did not work in home care, which meant they had to improvise regularly and without advance warning. They also worked with limited resources, which created certain challenges in their work. Participants found it very satisfying when they were able to deal with these challenges successfully. "You have to be very creative and inventive in coming up with solutions. If I think back to my time in the hospital, then I feel that what I'm doing now is real nursing. You have to work with the limited resources that are available. All the challenges that get dealt with successfully are moments of happiness in my work from which I derive new energy for new challenges. This is what makes our work so attractive." (OFG 3, homogenous OFG, bachelor's degree)

\section{DISCUSSION}

Being a "linchpin", in the sense of being the leading professional who collaborates intensively with other professionals and who takes the individual patient as the centre of care, is a very attractive role for home-care nurses. This result supports the World Health Organisation's (2015) call for people-centred and integrated health services delivery. In addition, home-care nurses indicate that the autonomy over patient care and their work autonomy are attractive aspects of their work. Previous research also showed that autonomy is important in home care (Anthony \& Milone-Nuzzo 2005, Ellenbecker et al. 2006, Maurits et al. 2015, Tummers et al. 2013). For instance, Maurits et al. (2015) found that home-care nursing staff who have autonomy are more engaged in their work and less likely to consider leaving the healthcare sector. The OFGs indicated that individual autonomy is accompanied with shared decision making with the patients and family caregivers, and with consultations with their immediate colleagues and other relevant professionals. This finding is in line with the research of Van Mierlo, Rutte, Vermunt, Kompier, and Doorewaard (2006), who found that nurses reported more individual autonomy when they felt supported by 
Groot, K. de, Maurits, E.E.M., Francke, A.L. Attractiveness of working in home care: an online focus group study among nurses. Health and Social Care in the Community: 2018, 26(1) e94-7 e101

their immediate colleagues. Hence autonomy over patient care is both an individual factor and a team-related trait.

Furthermore, the OFG discussions showed that home-care nurses often find working in a self-directed team attractive, a finding that is backed up by other research (Gray et al. 2015, Maurits et al. 2017, Tjepkema 2003). Home-care nurses in self-directed teams experience shared responsibility and the freedom to make decisions about the organisation of care, which is associated with the concept of organisational autonomy. Van Mierlo et al. (2006) have shown that team autonomy is positively related to individual autonomy, which may also explain the attractiveness of selfdirected teams.

Furthermore, home-care nurses find the variety in patient situations and nursing activities attractive; it prevents their day-to-day work from turning into boring routines. This finding is in line with research by Tourangeau et al. (2015), who show that having variety in patient situations is positively related with home care nurses' intent to remain employed in home care.

Interestingly, the abovementioned attractive aspects of working in home care were mentioned by home-care nurses of both levels of educational, although some specific job tasks (e.g. coaching team members and the formal needs assessment) were particularly relevant for those with a bachelor's degree. Nevertheless, in general, home-care nurses of both educational levels liked being "a linchpin", having autonomy and experiencing variety in patient situations and activities. We therefore recommend that professionals, managers and policy makers involved in recruiting new staff emphasise these positive aspects of working in home care. It is also important that these positive aspects are emphasised in magazines and on internet sites that are read by nurses. Given the growing need for care in the home, it is also important to ensure that current home-care nurses do not leave the home care sector. This implies that governments and care organisations, now and in the future, have to ensure the right financial and organisational conditions for home-care nurses to retain their linchpin role, and that it is also important to have autonomy and variation at work.

\subsection{Study strengths and limitations}

In 2014, the average age of nursing staff in home care was about 44 years and about $8 \%$ were male (AZW, 2014). Hence the average age of our sample is representative for the home-care sector. Unfortunately no male nurses were recruited for this study, which is a limitation for the generalisability. However, we reached data saturation for the female home-care nurses, which is a strength of this study. Saturation was confirmed as the last two OFGs produced no new aspects relevant for answering the research questions. Another strength is that we worked with a research team of three closely collaborating researchers, which allowed triangulation of data analyses and peer discussions.

Another feature of this study is that we only focused on the attractive aspects of working in home care. This choice was made since those aspects are important when recruiting staff. However, when it comes to retaining current personnel, it is also important to know what is not attractive about working in home care. Future research should therefore focus on gaining more in-depth knowledge about the negative aspects of working as a home-care nurse and strategies to mitigate these. With this knowledge, managers and policy makers can take action to prevent nurses from leaving the home-care sector. 
Groot, K. de, Maurits, E.E.M., Francke, A.L. Attractiveness of working in home care: an online focus group study among nurses. Health and Social Care in the Community: 2018, 26(1) e94-7 e101

\section{CONCLUSION}

Home-care nurses - both those with a bachelor's degree and those with an associate degree - find being a "linchpin", autonomy and variety in patient situations and nursing activities the main attractive aspects of their work. We recommend that these attractive aspects are emphasised in publicity materials and also by managers, lecturers, recruiters and policy makers who are involved in recruiting and retaining home care nursing staff.

\section{Acknowledgements}

The authors would like to thank all the home-care nurses who participated in this study.

\section{Source of funding}

This research received no specific grant from any funding agency in the public, commercial or not-for-profit sectors.

\section{Conflict of interest}

No conflict of interest has been declared by the authors.

\section{REFERENCES}

Amstrong-Stassen M.L.H.R. \& Cameron S.J. (2005) Concerns, satisfaction, and retention of Canadian community health nurses. Journal of community health nursing 22(4), 181-194

Anthony A, \& Milone-Nuzzo P. (2005) Factors attracting and keeping nurses in home care. Home Healthcare Nurse 23(6),372-377.

AZW. (2014) Personeelskenmerken 2014 - Branches [Staff characteristics 2014 - Branches] Available:

http://azwinfo.nl/iive/iive?presel code=br lft\&geolevel=branche\&geoitem=br05\&cat open code=nat pk lft, (accessed 19-05-16)

Braun V. \& Clarke V. (2006) Using thematic analysis in psychology. Qualitative Research in Psychology 3(2), 77-101.

Braun V. \& Clarke V. (2014) What can "thematic analysis" offer health and wellbeing researchers? International Journal of Qualitative Studies on Health and Well-being, DOI: doi: 10.3402/qhw.v9.26152 (accessed 13-09-2015).

De Bont M., Van Haaren E., Rosendal H. \& Wigboldus M. (2012) Expertisegebied wijkverpleegkundige [Area of expertise community nurse]. V\&VN, Utrecht. Available at: http://mgz.venvn.nl/Portals/30/Eerstelijn/Publicaties/wijkverpleegkundigen/20121106\%20E xpertisegebied\%20wijkverpl.pdf (accessed: 13-09-15)

De Putter I.D., Francke A.L., De Veer A.J.E. \& Rademakers J.J.D.J.M. (2014) Kennissynthese: De wijkverpleegkundige van vandaag en morgen.[Knowledge synthesis: The community nurse of today and tomorrow]. NIVEL, Utrecht

Ellenbecker C.H. (2004) A theoretical model of job retention for home health care nurses. Journal of Advanced Nursing 47(3), 303-310.

Ellenbecker C.H., Boylan L.N. \& Samia L. (2006) What home healthcare nurses are saying about their jobs. Home Healthcare Nurse 24(5), 315-324.

EUROFOUND (2013) More and better jobs in home-care services. Publications Office of the European Union, Luxembourg. Available at: http://bookshop.europa.eu/en/more-andbetter-job-in-home-care-services-pbTJ0213235/downloads/TJ-02-13-235-EN$\mathrm{C} / \mathrm{TJ} 0213235 E N C$ 002.pdf?FileName $=$ TJ0213235ENC 002.pdf\&SKU=TJ0213235ENC $P$ DF\&CatalogueNumber=TJ-02-13-235-EN-C (accessed 7-9-2016)

European Commission. (2013) Commission Staff Working Document: Long-term Care in Ageing Societies - Challenges and Policy Options. European Commission, Brussels. Available at: 
Groot, K. de, Maurits, E.E.M., Francke, A.L. Attractiveness of working in home care: an online focus group study among nurses. Health and Social Care in the Community: 2018, 26(1)e94-7 e101

http://ec.europa.eu/social/main.jsp?catld=89\&langld=nl\&newsld=1807\&moreDocuments=y es\&tableName=news, (accessed 13-09-15)

Genet N., Boerma W.G., Kringos D.S., Bouman A., Francke A.L., Fagerstrom C., Melchiorre M.G., Greco C. \& Devillé W. (2011) Home care in Europe: a systematic literature review.

BMC Health Service Research 11:207.

Genet N., Boerma W.G., Kroneman M., Hutchinson A. \& Saltman R.B. (2012) Home care across Europe: Current structure and future challenges. Available at: http://www.euro.who.int/ data/assets/pdf file/0008/181799/e96757.pdf (accessed 13-0915)

Gray B.H., Sarnak D.O. \& Burgers J.S. (2015) Home Care by Self-Governing Nursing Teams: The Netherlands' Buurtzorg Model. Available at: http://www.commonwealthfund.org/ /media/files/publications/casestudy/2015/may/1818 gray home care nursing teams buurtzorg model case study.pdf (accessed 31-08-2016)

Guest G., Bunce A. \& Johnson L. (2006) How many interviews are enough? An experiment with data saturation and variability. Field Methods18(1), 59-82.

Maurits E.E.M., De Veer A.J.E., Van der Hoek L.S. \& Francke A.L. (2015) Autonomous home-care nursing staff are more engaged in their work and less likely to consider leaving the healthcare sector: A questionnaire survey. International Journal of Nursing Studies 52(12), 1816-1823.

Maurits E.E.M., De Veer A.J.E., Groenewegen P.P. \& Francke A.L. (2017) Home-care nursing staff in self-directed teams are more satisfied with their job and feel they have more autonomy over patient care: a nationwide survey. Journal of Advanced Nursing 00(0), 000000. doi: 10.1111/jan.13298

Ministry of Health, Welfare and Sports. (2015) Kamerbrief over bekostiging wijkverpleging [Letter to House of Representatives about funding home care]. Available at: https://www.rijksoverheid.nl/documenten/kamerstukken/2015/05/19/kamerbrief-overbekostiging-wijkverpleging (accessed 13-09-15)

Reid D.J. \& Reid F.J.M. (2005) Online focus groups: An in-depth comparison of computermediated and conventional focus group discussions. International Journal of Market Research 47(2),131-162.

Tates K., Zwaanswijk M., Otten R., Van Dulmen S., Hoogerbrugge P.M., Kamps W.A. \& Bensing J.M. (2009) Online focus groups as a tool to collect data in hard-to-include populations: examples from paediatric oncology. BMC Medical Research Methodolgy, 9:15.

Tjepkema S. (2003) The learning infrastructure of self-managing work teams. PhD Thesis. University of Twente, Enschede

Tourangeau A.E., Patterson E., Saari M., Thomson H. \& Cranley, L. (2015) Work-related factors influencing home care nurses intent to remain employed. Health care management review, DOI: 10.1097/HMR.0000000000000093 (accessed 31/8/2016).

Tummers L.G., Groeneveld S.M. \& Lankhaar M. (2013) Why do nurses intend to leave their organization? A large-scale analysis in long-term care. Journal of Advanced Nursing 69(12), 2826-2838.

United Nations. (2013) World Population Ageing 2013. United Nations, New York. Available at:

http://www.un.org/en/development/desa/population/publications/pdf/ageing/WorldPopulatio nAgeing2013.pdf (accessed 13-09-15)

Van Mierlo H., Rutte C.G., Vermunt J.K., Kompier M. \& Doorewaard J. (2006) Individual autonomy over work teams: The role of team autonomy, self-efficacy, and social support. European Journal of Work and Organizational Psychology 15(3), 281-299.

Weston M.J. (2008) Defining control over nursing practice and autonomy. The Journal of Nursing Administration 38(9), 404-408.

World Health Organisation (2015) WHO global strategy on people-centred and integrated health services: interim report. World Health Organisation, Geneva

Zwaanswijk M. \& Van Dulmen S. (2014) Advantages of asynchronous online focus groups and face-to-face focus groups as perceived by child, adolescent and adult participants: a survey study. BMC Research Notes, 7:756. 
Groot, K. de, Maurits, E.E.M., Francke, A.L. Attractiveness of working in home care: an online focus group study among nurses. Health and Social Care in the Community: 2018, 26(1)e94-7 e101

\section{TABLES AND FIGURES}

\section{Table 1 Interview guide for online focus groups}

Given the iterative process of qualitative research, the interview guide could be adjusted based on new insights from data analysis.

First open question:

What do you find attractive about your work as a home-care nurse?

Possible follow-up questions

Autonomy over patient care:

Can you say something about whether working independently in the patient's home is important for the attractiveness of your work?

Do you find it important to be able to make independent decisions concerning the patient care? Do you find this important for the attractiveness of your work? Can you elaborate on your answer?

What does the authority to perform a formal care needs assessments mean for the attractiveness of your work? Can you elaborate on your answer?

Work autonomy:

Do you find it important to experience freedom and discretion in making decisions about work methods? Do you find this important for the attractiveness of your work? Can you elaborate on your answer?

Do you find it important to experience freedom and discretion in making decisions about work scheduling? Do you find this important for the attractiveness of your work? Can you elaborate on your answer?

Organisational autonomy:

Do you find it important to be involved in decision making about the practice setting and contextual matters? Do you find this important for the attractiveness of your work? Can you elaborate on your answer?

Self-directed teams:

Do you find it important for the attractiveness of your work to be working in a selfdirected team? Can you elaborate on your answer?

Follow-up question for all previous questions:

Do you think there are differences between home-care nurses with different levels of education in the aspects that they find attractive in their work? 
Groot, K. de, Maurits, E.E.M., Francke, A.L. Attractiveness of working in home care: an online focus group study among nurses. Health and Social Care in the Community: 2018, 26(1)e94-7 e101

Table 2 Characteristics of the participants in the online focus groups $(\mathbf{n}=\mathbf{3 8})$

\begin{tabular}{|l|l|}
\hline & number or mean (range) \\
\hline Age (years) & $42.5(22-64)$ \\
\hline Work experience (years) & $14.4(1-40)$ \\
\hline Working hours per week & $27.9(12-38)$ \\
\hline Gender & 38 \\
Female & \\
\hline Education level & 18 \\
Bachelor's degree & $20^{\mathrm{a}}$ \\
Associate degree & \\
\hline Kind of team & 27 \\
Self-directed & 11 \\
Non-self-directed & \\
\hline
\end{tabular}

${ }^{\mathrm{a}}$ Four nurses with an associate degree were following a bachelor's programme in nursing during this study

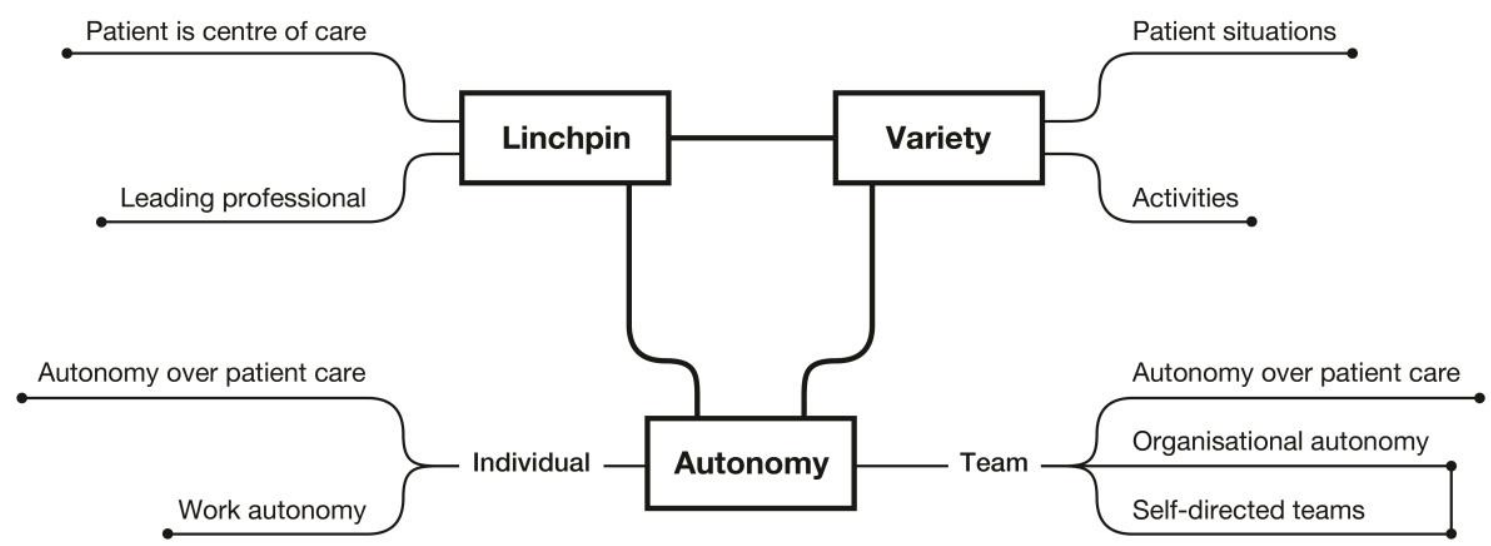

Figure 1: Thematic map 